\title{
Homeschooling e a negação do direito à educação: um desdobramento do estado neoliberal
}

\author{
Homeschooling e a negação do direito à educação: \\ um desdobramento do estado neoliberal
}

\author{
Clemildo Anacleto da Silva ${ }^{1}$ \\ Emanoel Rodrigues Almeida ${ }^{2}$ \\ Karla Érika Ferreira Ferro ${ }^{3}$
}

\section{RESUMO}

Há uma relação de determinação recíproca entre os direitos humanos e o Estado. 0 presente texto pretende compreender como se dá essa relação no contexto do neoliberalismo. Os objetivos específicos são: 1) demonstrar a forma do Estado neoliberal; 2) compreender como tal forma de Estado determina a criação dos direitos humanos e por fim 2) apresentar o homeschooling como uma expressão da privatização do direito à educação.Trata-se de uma pesquisa de caráter qualitativo do tipo bibliográfico, baseada nas contribuições de teóricos como: Lukács (2012), Antunes (2003), Padilha (2014), Santomé(2003), Gentilli (1998), entre outros. Percebeu-se que o homeschooling é uma expressão do Estado Neoliberal em sua empreitada de privatização dos direitos humanos, neste caso do direito à educação.

\section{PALAVRAS-CHAVE}

Neoliberalismo; Direitos Humanos; Educação; Homeschooling.

\footnotetext{
${ }^{1}$ Mestre em Educação pelo Centro Universitário La Salle. Mestre e Doutor em Ciências da Religião pela Universidade Metodista de São Paulo. Professor titular do Centro Universitário Metodista IPA.

${ }^{2}$ Mestre e Doutor em Educação Brasileira pela Universidade Federal do Ceará. Pós doutorando em Educação Profissional e Tecnológica pelo PROFEPT. Professor titular do Instituto Federal do Ceará.

${ }^{3}$ Bacharel em Direito pelo Centro Universitário Christus. Especialista em Direito Previdenciário pela FAEPI. Advogada.
} 


\section{ABSTRACT}

There is a relationship of reciprocal determination between human rights and the state. This text intends to understand how this relationship occurs in the context of neoliberalism. The specific objectives are: 1) to demonstrate the shape of the neoliberal state; 2) understand how such a form of state determines the creation of human rights and finally 2) present homeschooling as an expression of the privatization of the right to education. This is a qualitative research of the bibliographic type, based on the contributions of theorists such as:Lukács (2012), Antunes (2003), Padilha (2014), Santomé (2003), Gentilli (1998), among others. Homeschooling is an expression of the Neoliberal State in its endeavor to privatize human rights, in this case the right to education.

\section{KEYWORDS}

Neoliberalism; Human rights; Education; Homeschooling. 


\section{INTRODUÇÃo}

Os direitos humanos nasceram no contexto do capitalismo e, por isso, são frutos do embate entre os trabalhadores e donos dos meios de produção. Embora eles representem conquistas dos trabalhadores, predominantemente os direitos humanos foram determinados pelos interesses da classe que dominou a riqueza material ao longo do desenvolvimento do modo de produção capitalista.

Por terem brotado no contexto histórico do capitalismo, os direitos humanos guardam uma relação direta com a forma de Estado capitalista. Os direitos civis, por exemplo, foram determinados historicamente, pela forma de Estado liberal. Em função dessa determinação, os direitos humanos mantêm uma relação de dependência ontológica com o Estado capitalista, por isso são obrigados a cumprir as exigências dessa forma de Estado. Apesar desta dependência, no entanto, os direitos humanos estabelecem uma relação de autonomia relativa com as formas de Estado. Assim sendo, há uma relação de determinação recíproca entre as formas de Estado capitalistas e os direitos humanos.

Esse texto surgiu da necessidade de compreender como se dá esse processo de determinação recíproca entre o Estado e os diretos humanos no contexto do Estado neoliberal. Dessa forma, procura compreender, em linhas gerais, as relações entre o neoliberalismo, a reforma do Estado e o direito à educação. Os objetivos específicos são: 1) demonstrar como se processa o neoliberalismo; 2) compreender a reforma do Estado como um desdobramento do neoliberalismo; 3) apresentar o homeschooling como uma expressão da privatização do direito à educação.

Esse texto foi produzido a partir de uma pesquisa qualitativa do tipo bibliográfica, baseada nas contribuições de teóricos como: Lukács (2012), Antunes (2003), Padilha (2014), Santomé(2003), Gentilli (1998), entre outros.

Na primeira parte do texto, iremos apresentar o neoliberalismo e suas características; na segunda parte, apresentaremos a reforma do Estado como um subproduto do neoliberalismo; por último apresentaremos o homeschooling como uma expressão da privatização da educação.

\section{NEOLIBERALISMO}

Com o fim da Segunda Guerra Mundial, decretado nos corpos de quase 150 mil seres humanos, atingidos pelas bombas de Hiroshima e Nagasaki entre os dias 6 e 10 de agosto de 1945, o Japão rendeu-se completamente e a humanidade, talvez, ainda sem saber, entrava em um período que duraria quase meio século, conhecido como Guerra Fria e marcado, dentre outros fenômenos, pela corrida armamentista e rivalidade entre americanos e soviéticos.

Ainda durante a Segunda Grande Guerra, as nações mais industrializadas do mundo, os Estados Unidos da América e alguns países da Europa, apresentaram quedas consideráveis em suas atividades econômicas. Com o visível crescimento tecnológico da informação e da comunicação, a distância entre as nações parecia diminuir e o surgimento de uma crise de proporções maiores se apresentava inevitável. Dentro desse contexto, a Organização das Nações Unidas (ONU), reuniu em 1944, nos EUA, representantes de cerca de 44 países num encontro que ficou conhecido como Conferência Internacional de Breton Woods.

O objetivo central dessa conferência era a formação de um sistema de cooperação econômica para, com vistas ao crescimento econômico, fornecer assistência financeira aos países em crise e fortalecer o comércio mundial, enfraquecido pela Guerra. Os EUA apareciam como a nação mais interessada nessas propostas, sob o pretexto de restaurar a economia mundial. Essa reestruturação, todavia, deveria constituir uma nova economia, totalmente aberta e unificada sob seu controle, o que garantiria, principalmente, o livre acesso a novos mercados. Dentro desse contexto, parece, de fato, que a Guerra Fria se constitui palco propício à criação de novos postulados econômicos com vistas à retomada do desenvolvimento econômico mundial.

Com a queda da taxa de lucro, dada, dentre outros elementos causais, pelo aumento do preço da 
força de trabalho, conquistado durante o período pós-45 e pela intensificação das lutas sociais dos anos de 1960, que objetivavam o controle social da produção; o esgotamento do padrão de acumulação taylorista/fordista de produção, dado pela incapacidade de responder à retração do consumo que se acentuava; a hipertrofia da esfera financeira, que ganhava relativa autonomia frente aos capitais produtivos; a maior concentração de capitais graças às fusões entre as empresas monopolistas e oligopolistas; a crise do welfarestateou do "Estado de bem-estar social" e dos seus mecanismos de funcionamento acarretando a crise fiscal do Estado capitalista e a necessidade de retração dos gastos públicos e sua transferência para o capital privado; e, ainda, o incremento acentuado das privatizações, tendência generalizada às desregulamentações e à flexibilização do processo produtivo, dos mercados e da força de trabalho, entre tantos outros elementos contingentes que exprimiam esse novo quadro crítico, surge e, rapidamente se fortalece após a Segunda Guerra Mundial a Doutrina Neoliberal:

...que se opunha a todo o pensamento econômico de inspiração keynesiana e às políticas dele consequentes, como o incipiente Estado do Bem-estar social (Estado-providência) e às políticas econômicas de cunho anti-cíclico. 0 austríaco Friedrich August von Hayek e o norteamericano Milton Friedman, principais formuladores dessa corrente conservadora, criticavam o caráter autoritário desse Estado, que com seus encargos sociais e sua atuação reguladora, estaria impedindo a realização das liberdades individuais e a competição que levava à prosperidade econômica. A partir desse diagnóstico, propunham o afastamento do Estado em relação às atividades econômicas, bem como a realização de inúmeras reformas institucionais que permitissem a livre competição e a livre circulação dos capitais, de forma que a única ação reguladora possível fosse a do mercado. Privatização de todos os setores da economia nacional, transferência de serviços públicos ao setor privado, desregulamentação do sistema financeiro, redução dos encargos e direitos sociais como um todo, redução dos gastos governamentais, entre outras, são algumas das principais propostas do neoliberalismo. A primeira experiência de implantação de políticas neoliberais ocorreu no Chile, comandado pela Ditadura do General Pinochet, ainda nos anos 70.Seu "ressurgimento" correspondia à necessidade do sistema capitalista de re-dinamizar o processo de acumulação, que entrara em crise na medida em que o padrão de financiamento público (estatal) da economia se tornava insuficiente para suprir as necessidades de expansão permanente do capital. $\mathrm{O}$ aumento exagerado dos déficits fiscais converteu-se em ameaça ao próprio sistema, na medida em que o Estado não podia mais financiar tais encargos. As reformas neoliberais, que identificavam o problema não no capital, e sim no Estado, surgem então como a panaceia: reduzir encargos sociais, encargos trabalhistas, saneamento fiscal (redução dos gastos públicos e privatizações), redução de direitos sociais, entre outras. Nos anos 1990, sobretudo na América Latina, o receituário neoliberal assumiu ares de hegemonia.(ANTUNES, 2003, p. 29-30).

Em 1989 ocorreu, na capital dos Estados Unidos, o Consenso de Washington, que pode ser considerado um marco no processo de desenvolvimento e ampliação do neoliberalismo no mundo. O conjunto de ações e reformas indicadas no evento representa a efervescência política enfrentada por muitos dos países em desenvolvimento no final do século XX. Suas propostas, no entanto, não apresentam novidades, visto que já eram amplamente divulgadas por governos como o dos EUA e Reino Unido desde as décadas de 1970 e 1980.

Para o economista John Willianson ${ }^{4}$, sob o prisma da aceleração do desenvolvimento, as recomendações da referida reunião deram-se em torno da abertura econômica e comercial, ampliação da economia de mercado e controle fiscal macroeconômico. Deste modo, pode-se elencar como premissas básicas do Consenso de Washington:

\footnotetext{
${ }^{4}$ John Williamson, economista, nasceu na Inglaterra em 1937. É conhecido internacionalmente como o homem que cunhou o termo "Consenso de Washington". Entre 1968 e 1970, durante o governo trabalhista (centro-esquerda) de Harold Wilson foi consultor econômico do tesouro britânico. Foi conselheiro do Fundo Monetário Internacional no período entre 1972 e 1974.
} 
- Disciplina fiscal, caracterizada pelo corte de gastos por parte do Estado, especialmente quanto à diminuição de custos e funcionários;

- Reforma fiscal e Reforma tributária, visando à redução de tributos às empresas pela reformulação dos sistemas de arrecadação de impostos;

- Privatização de empresas estatais, a fim de garantir uma ampliação progressiva da ação privada em todos os setores, sejam eles comerciais ou de infraestrutura;

- Abertura comercial e econômica dos países, pela diminuição do protecionismo;

- Desregulamentação progressiva do controle econômico e das leis e direitos trabalhistas.

Ao adotar o receituário de medidas apresentadas pelo Consenso de Washington, o governo brasileiro passou a implementar, na década de 1990, um amplo conjunto de reformas, inclusive educacionais, com vistas à adequação ao novo padrão econômico mundial. 0 neoliberalismo se estrutura, na esteira desse processo, sobre a disciplina fiscal, reforma de estado, privatização, abertura comercial e desregulamentação dos direitos sociais.

\section{A REFORMA DO ESTADO COMO SUBPRODUTO DO NEOLIBERALISMO}

Em 1995, foi criado no Brasil o Ministério da Administração Federal e Reforma do Estado, como marco da institucionalização da reforma do aparelho estatal. Sob a chefia de Bresser Pereira, o referido Ministério postulava um Estado mínimo quanto à intervenção na economia e menos "dispendioso". No entanto, vale dizer, que foi ainda sob o governo Collor de Melo, iniciado em 1990, que o Estado brasileiro aderiu ao conjunto de indicações dos organismos multilaterais, capitaneados pelo Banco Mundial. Delineia-se a constituição de um Estado gestor, que atribui para si a lógica empresarial capitalista. Não obstante, como consequência desse processo, muitas mudanças ocorreram na esfera da educação brasileira.
Segundo o verbete elaborado por Lalo Watanabe Minto, a relação entre Reforma do Estado e Educação no Brasil constitui uma:

Série de amplas reformas institucionais iniciadas ao final dos anos 1980, no Brasil, com o intuito de adequar o Estado brasileiro aos ditames do novo padrão da acumulação capitalista. Nos anos 1990, após as eleições presidenciais de 1994, ganha maior corpo e torna-se uma prioridade do governo federal brasileiro... As diretrizes fundamentais da reforma advêm da doutrina neoliberal e expressam-se na necessidade de reestruturar todas as grandes áreas de atuação do Estado, com especial destaque para as sociais: educação, saúde, previdência social e legislação trabalhista. De um modo geral, preconiza-se a redução dos gastos estatais, tidos como ineficientes e ineficazes, e a transferência de tais "serviços" para o setor privado, supostamente mais eficiente, flexível e menos burocrático. Da mesma forma, a reforma do estado pressupõe a criação de condições favoráveis à atuação do setor privado - aquele que declara visar lucros, ou não - tais como a oferta de incentivos fiscais, a garantia de mercados cativos e programas governamentais que possibilitem o acesso das camadas mais pobres da população brasileira ao ensino pago, sobretudo no nível superior.

Na análise de Dourado, Catani e Oliveira, a reforma do Estado experimentada pelo Brasil no final do século XX, da qual a educação foi parte constituinte, resultou de um contexto global de reestruturação do sistema capitalista, visto que com a:

Crise do capitalismo nos anos 1970 efetuou-se [na década de 1990, no Brasil] a reforma do Estado e, subjacente a esse processo, a reforma do sistema educativo no Brasil, em sintonia com os organismos multilaterais, resultando na crescente ampliação da esfera privada em contraposição ao alargamento dos direitos sociais (DOURADO, CATANI \& OLIVEIRA, 2003, p. 17).

Para Oliveira (2001), toda a discussão acerca da relação entre educação e desenvolvimento dos anos de 1990, no Brasil, deu-se "pela exigência de responder ao padrão de qualificação emergente no contexto de reestruturação produtiva e de glo- 
balização da economia, ocupando lugar de destaque nas políticas educacionais" (p. 105). Ou seja, a adoção de um viés economicista na condução das políticas educacionais, com vistas à formação de "capital humano".

As últimas décadas do século XX trazem à tona um cenário de crise estrutural, na medida em que a crise do taylorismo e do fordismo constitui expressão fenomênica desse processo (MÉSZÁROS, 2000; ANTUNES, 2003). Durante o período marcado fundamentalmente pelo apogeu do fordismo e da bemsucedida fase keynesiana, o capitalismo atravessou uma longa fase de acumulação de capitais. No entanto, a partir de 1970, evidências históricas corroboram com a caracterização de uma crise profunda, sem precedentes.

A adequação do sistema educacional brasileiro, a partir da década de 1990, portanto, está atrelada às demandas do processo de acumulação do capital num contexto de crise, "ou seja, reguladas e subordinadas pela esfera privada e à sua reprodução" (FRIGOTTO, 1996). 0 direcionamento da educação passa a sofrer fortes influências da lógica empresarial, ao mesmo tempo em que currículos são redesenhados e a gestão educacional e escolar passam a implementar em seu funcionamento as características da qualidade total. A educação entra na ordem do dia como instrumento eficaz de redução da pobreza e formação de "capital humano".

A influência exercida pelo Banco Mundial nos processos de reforma do Estado, especialmente na particularidade brasileira, implementados a partir do cenário descrito até aqui, se coaduna perfeitamente com a ação dessa instituição no desenvolvimento econômico mundial. Primeiro pelo volume de empréstimos concedidos e segundo, pela abrangência de diversas áreas de atuação (SOARES, 2009). De fato, qualquer análise em torno do processo de reestruturação neoliberal dos países em desenvolvimento, e de como a educação se insere nesse fenômeno, não pode prescindir a uma exposição do conteúdo político e filosófico que cerca as políticas de ajuste estrutural conduzidas pelo referido banco.

Confirma Leher (2001), que, não obstante o espaço de proporções jamais vistas dedicado à edu- cação pelo do Banco Mundial - denominado pelo autor como o Ministério Mundial da Educação, a preocupação principal que move as ações daquele Banco se referem propriamente ao desenvolvimento da educação dos países periféricos com vistas à estabilidade política, a ser assegurada por um sistema educacional que garanta a incontestabilidade das novas condições de produção, construindo, ao mesmo tempo, nos indivíduos, as 'disposições ideológicas' necessárias ao ajustamento à "nova configuração histórico e social”. A “educação é a principal variável da probabilidade de que um dado indivíduo ultrapasse a linha da pobreza" (LEHER, 1998, p. 186).

\section{A PRIVATIZAÇÃO DA EDUCAÇÃO: O HOMESCHOOLING}

Para a consecução de um projeto educacional organicamente articulado à reforma do Estado ora apresentada, na leitura feita por Coraggio (2009) deve-se destacar o empenho do Banco Mundial em induzir os sistemas de educação à descentralização. A justificativa para que isso ocorra reside na compreensão aparentemente verdadeira de que cada distrito ou estabelecimento de ensino possui, dado o conhecimento das diversas circunstâncias locais, maior competência para a resolução de problemas oriundos da prática educativa. Ainda como consequência direta da citada descentralização, o Banco aponta para uma redução progressiva da capacidade dos interesses tradicionais, diretamente relacionados à ação dos sindicatos de professores, associações estudantis, etc.

... a escola é vista como empresa que monta e organiza insumos educacionais e produz recursos humanos com um certo nível de aprendizado. Pretende-se que o faça, como qualquer empresa submetida à concorrência, ao menor custo possível. Para definir políticas, o modelo sugere realizar um estudo empírico dos "insumos escolares" e de seus custos, relacionando suas variações às do nível de aprendizagem alcançado (CORAGGIO, 2009, p. 107). 
Ainda conforme o citado autor, o grande objetivo das diversas decisões descentralizadas a serem orquestradas refere-se ao desenvolvimento das capacidades básicas de aprendizagem no ensino primário e, quando este obtiver certo êxito, no nível secundário inferior, voltado preferencialmente para a produção de "trabalhadores flexíveis".

Semelhante ao que ocorreu em outros países da América Latina, o documento que orienta toda a Reforma da Educação Básica no Brasil é resultado da Conferência Mundial sobre Educação para Todos ocorrida em 1990, em Jomtien, na Tailândia. A referida Conferência, que contou com a participação de mais de 150 países, lançou um novo paradigma quanto ao tratamento das questões educacionais no mundo inteiro, sob a regência da Organização das Nações Unidas (ONU), através de alguns de seus principais organismos, dentre os quais se destaca o Banco Mundial. Tratou-se da Declaração mundial sobre educação para todos e do Plano de ação para satisfazer as necessidades básicas de aprendizagens

Os compromissos assumidos pelos governos na Conferência de Jomtien promoveram uma série de reformulações na política educacional, expressas em sua maioria no conjunto de planos, leis e documentos elaborados nos anos posteriores. 0 Plano Decenal de Educação para todos, elaborado em 1993, é o primeiro grande movimento assumido pelo Brasil com vistas à valorização da educação básica como epicentro da nova ação educativa. No entanto, todo o plantel de leis educacionais posteriores (LDB 9394/1996; PCNs; DCNs, etc.) traz, de certa forma, em seu conteúdo as premissas fundamentais de um projeto educacional reformado e adequado às novas exigências ora anunciadas.

É nesse contexto que se situa o homeschooling, motivado pelo movimento neoliberal, associado ao crescimento da extrema direita, que, carrega um discurso de acabar com um comunismo, que sequer existe, assistimos a da tramitação da Proposta de Lei no $2401 / 2019$ com reais possibilidades de regulamentação e implantação do ensino domiciliar em nosso país.

0 termo em inglês cuida de uma modalidade de ensino doméstico, substitutivo do ensino formal escolar, em que as crianças são educadas em casa, tendo os pais e/ou professores particulares como instrutores. Nas últimas décadas, esse modo de ensino tem conquistado adeptos em vários países do mundo em contraposição à escolarização:

Os adeptos do movimento de educação na casa ganham popularidade no início dos anos de 1980, especialmente nos Estados Unidos da América, e espalham-se pelos continentes, havendo registros, nas décadas seguintes, de experiências de educação doméstica em todo o mundo.(VASCONCELOS, 2017, p.126)

Segundo dados do Departamento Nacional de Educação dos Estados Unidos ${ }^{5}$, no ano letivo de 2012, cerca de 1,77 milhões de estudantes em entre 5 e 17 anos foram educados em casa, o que corresponde a expressivos 3,4\% do alunado.

Em geral, as famílias defensoras da educação domiciliar justificam que a educação estatal não é de qualidade e que querem educar segundo padrões e preceitos religiosos. Entre os pesquisadores que defendem a desescolarização, se encontra Ilich, para quem a educação seria apenas um desperdício de verba pública, e que atingir as suas finalidades formativas seria tarefa quase inatingível:

Em todo o mundo a escola tem um efeito anti-educacional sobre a sociedade: reconhece-se a escola como a instituição especializada em educação. Os fracassos da escola são tidos, pela maioria, como prova de que a educação é tarefa muito dispendiosa, muito complexa, sempre misteriosa e muitas vezes quase impossível. (ILICH, 1976, p.16)

Entre os críticos desse modelo, Santomé destaca que o homeschooling carece de integração social e destaca a importância da convivência escolar:

[...] a educação numa instituição escolar obriga a estabelecer um maior número de relações; as aulas agrupam, normalmente, entre 20 a 25 estudantes cada; nestas, os rapazes e as raparigas

\footnotetext{
${ }^{5}$ BBCBrasil.com. Educação domiciliar nos Estados Unidos. Disponível em: https://www.bbc.com/portuguese/noticias/2013/11/131031_educacao_domiciliar_eua_mdb_ac. Acesso em: 23 set. 2019.
} 
caracterizam-se por possuir distintos ritmos de aprendizagem, diferente bagagem cultural, expectativas díspares, diferentes capacidades e modalidades de inteligência, distinto sexo, etc., algo que converte esse grupo numa pequena representação do que é o mundo externo à aula, no qual eles vivem. (SANTOMÉ, PARASKEVA \& APPLE, 2003, p.46).

No Brasil, de acordo a evolução normativa pátria, é possível inferir que a educação formal (escolarizada) é tida como obrigatória desde a Constituição Federal de 1934, sendo responsabilidade compartilhada das famílias e do Estado. No entanto, foi mesmo a partir da Constituição cidadã de 1988 , vigente em nossos dias, que se versou mais amplamente sobre o direito à educação em dez artigos específicos (VIEIRA, 2007). Inclusive, os constituintes cuidaram de inserir o direito à educação no rol dos direitos sociais do seu art. 6.

Já que a Constituição rege toda a normatividade do nosso país, todo o ordenamento infra-constitucional e legal ser com ela compatível. É o que preleciona Padilha:

Assim, o controle de constitucionalidade pode ser conceituado como a análise de conformação da norma infraconstitucional (objeto) à norma constitucional (parâmetro), em razão da relação imediata de conformidade vertical entre aquela e esta, com o fim de impor sanção de invalidade à norma que seja incompatível com o bloco de constitucionalidade. (PADILHA, 2014, p. 214)

Assim, tem-se que a questão do homeschooling foi discutida na corte constitucional (STF) para esse chamado controle de constitucionalidade, tendo seu desfecho em setembro de 2018 em sede de Recurso Extraordinário no 888815/RS com repercussão geral. 0 acórdão em comento foi lavrado pelo Ministro Alexandre de Moraes, que foi quem primeiro abriu a divergência vencedora.

Em suma, concluíram que existem quatro espécies de ensino doméstico: a desescolarização radical; a desescolarização moderada; o ensino domiciliar puro e o homeschooling (o ensino domiciliar utilitarista ou por conveniência circunstancial). Decidiram que os três primeiros seriam inconsti- tucionais, mas que este último não encontra vedação expressa na Constituição, podendo ser regulamentado pelo Congresso Nacional para executado pelas famílias conforme conveniência circunstancial, devendo o ensino ser submetido à fiscalização e avaliação regular do poder público.

0 que nos soa como paradoxal, tendo em vista que este Estado que carece de educação de qualidade ou fiscalização adequada da educação privada, é o mesmo que vai acompanhar e avaliar o ensino doméstico executado pelas famílias.

Apesar do homeschooling aguardar apenas a regulamentação de lei, entende-se pela extração dos ditames da $\mathrm{CF} / 88$ que tocam à educação, que não há margem para o ensino exclusivamente doméstico dos educandos.

Senão, veja-se o Art. 208, § 3ํ da CF/88: “Compete ao Poder Público recensear os educandos no ensino fundamental, fazer-lhes a chamada e zelar, junto aos pais ou responsáveis, pela frequência à escola." Muito embora a Constituição não faça vedação ao ensino domiciliar, é expressa quanto à educação formal escolar quando fala em zelo pela frequência à escola, a nosso sentir, dispensando a expressa proibição ao ensino doméstico por uma questão lógica.

Sendo a educação um direito fundamental do ser humano, para OLIVEIRA \& ADRIÃO, deve ser compulsório e obrigatório, se caracterizando assim como um direito e um duplo dever, se referindo:

ao dever do Estado de garantir a efetivação desse direito e, de outro, ao dever do pai ou responsável de provê-la, uma vez que passa a não fazer parte do seu arbítrio a opção de não levar o filho à escola. (OLIVEIRA \& ADRIÃO, 2007, p.13).

Dessa forma, o indivíduo em idade escolar passa a ser credor desse direito, que exige além do acompanhamento da família, a prestação positiva estatal, tão condenada pelo ideário neoliberal.

A prática do ensino domiciliar em detrimento do escolar frustra a finalidade constitucional dada à educação no Art. 205 da Magna Carta, na medida em que a formação do indivíduo deve ser integral, visando seu desenvolvimento pleno, não apenas 
intelectual, mas também cidadã, artística e social, em contato com a diversidade de pensamento e de ideias, senão veja-se:

Art. 205 - A educação, direito de todos e dever do Estado e da família, será promovida e incentivada com a colaboração da sociedade, visando ao pleno desenvolvimento da pessoa, seu preparo para o exercício da cidadania e sua qualificação para o trabalho.

0 homeschooling, em qualquer de suas vertentes, fere os princípios constitucionais do ensino elencados no art. 206 da CF/88, entre eles, o de igualdade de condições para acesso e permanência na escola; o do pluralismo de ideias e de concepções pedagógicas e o de coexistência de instituições públicas e privadas de ensino. ${ }^{6}$

A edição de lei para regulamentar o homeschooling se apresenta como a legalização do esvaziamento da obrigação estatal prevista na constituição, no art. 208, I e IV, na medida em que o dever do Estado para com a educação se efetiva com a oferta de educação básica obrigatória e gratuita dos 4 (quatro) aos 17 (dezessete) anos de idade, assegurada inclusive sua oferta gratuita para todos os que a ela não tiveram acesso na idade própria e educação infantil, em creche e pré-escola, às crianças até 5 (cinco) anos de idade. 0 Estado deve assegurar o direito fundamental à educação das crianças e dos adolescentes, resguardando inclusive da negligência das famílias em não levá-los ao seio escolar.

Vale ressaltar que no nosso ordenamento jurídico pátrio, de acordo com o art. 249 do Código Penal $^{7}$, configura crime de abandono intelectual não levar as crianças em idade escolar para a escola.

Ocorre que, longe de ser uma questão jurídica que comporte ponderações de constitucionalidade ou legalidade, essas novas políticas educacionais atendem ao novo modelo neoliberal de eco-

${ }^{6}$ BRASIL. Constituição (1988). Constituição da República Federativa do Brasil. Disponível em: http://www.planalto.gov.br/ ccivil_03/constituicao/constituicao.htm. Acesso em 2 jul.2019. ${ }^{7}$ BRASIL. Código Penal (1940). Código Penal Brasileiro. Disponível em: http://www.planalto.gov.br/ccivil_03/decreto-lei/ del2848compilado.htm. Acesso em 10 ago.2019. nomia, no âmbito da educação básica, o faz com o homeschooling, entre outras práticas, e no ensino superior, com o Future-se. Isso porque o poder material é que determina os rumos da sociedade no que toca à educação, à saúde, mesmo que à deriva da norma.

Desse modo, a educação é direito social apenas em sentido formal, sem resultado prático. Vira mercadoria, empreendida por uma pequena parte da sociedade, em que o acesso a ela é igualmente restrito, preleciona Gentilli que:

Longe de ser um direito do qual gozam os indivíduos, dada sua condição de cidadãos, deve ser transparentemente estabelecida como uma oportunidade que se apresenta aos indivíduos empreendedores, aos consumidores responsáveis, na esfera de um mercado flexível e dinâmico (o mercado escolar). (...) Reduzida à sua condição de mercadoria, a educação só deve ser protegida não por supostos direitos sociais, mas pelos direitos que asseguram o uso e a disposição da propriedade privada por parte de seus legítimos proprietários. (GENTILLI, 1998, p.21).

A educação no neoliberalismo, na medida em que é vista como mercadoria, deixa de ser protegida pelo Estado como direito social e enquanto obrigação de efetivação e passa à sua tutela apenas como um direito de propriedade de instituições privadas que a executam. Isto porque o Estado no capitalismo é o guardião dos interesses privados.

0 direito à educação só se realiza dentro dos limites do desenvolvimento da propriedade, parecendo-nos impossível de se realizar frente a todos os indivíduos enquanto direito.

\section{CONSIDERAÇÕES FINAIS}

Os direitos humanos guardam uma relação direta com o Estado Neoliberal. Para que essa forma de Estado se realizasse foi necessário haver profundas reformas em todos os campos sociais, inclusive na educação. 0 Estado neoliberal realizou-se através da redução do tamanho do Estado, da liberalização do mercado, da privatização dos serviços públicos, e consequente, da redução dos direitos sociais. 
Embora seja uma prática assumida em diferentes lugares do mundo, a educação exclusivamente domiciliar representa um grande retrocesso no campo da educação, deixando grandes lacunas na formação dos indivíduos, uma vez carece de pleno convívio social entre os pares e nega a possibilidade do acesso à educação pública compulsória, gratuita e de qualidade.

Aqui no Brasil,embora o governo aponte para a aplicação desta prática, com a possibilidade aberta pelo STF, o homeschooling depende apenas de regulamentação pelo Congresso Nacional, mas apesar disso, ela ainda não é consenso e vem sendo alvo de críticas não só no âmbito jurídico, no que toca às incompatibilidades com o ordenamento legal pátrio, mas também está no debate educacional e social.

O homeschooling tornou-se em todo o mundo uma expressão da privatização do direito à educação, delegando às famílias a responsabilidade for- mativa das crianças e adolescentes à seu critério, sob o argumento da autonomia privada, enquanto o Estadose escusa de suas obrigações para com a educação, inclusive para com aqueles que não podem suportar os custos da formação privada de seus filhos, ferindo de morte os princípios constitucionais que deveriam reger o ensino para embasar uma formação plural aos educandos.

Essa privatização do direito à educação, de fato, é uma determinação da sociabilidade capitalista que, nos seus limites objetivos, é impossibilitada de oferecer uma educação gratuita, pública e de qualidade para todos. Tanto a política quanto o direito, por sofrerem as determinações da totalidade da sociabilidade capitalista, foram obrigados a cumprir as exigências de tal sociabilidade. Tal privatização nos aponta que a luta da humanidade deve se estender para além do campo da política ou do próprio direito e dirigir-se ao caráter privado que essa forma de sociabilidade assume no capitalismo. 


\section{REFERÊNCIAS}

ANTUNES, R. Os Sentidos do Trabalho: ensaio sobre a afirmação e a negação do trabalho.São Paulo: Boitempo, 2003.

BOBBIO, Norberto. A era dos Direitos. São Paulo:Elsevier, 2004.

BRASIL. Constituição (1988). Constituição da República Federativa do Brasil. Disponível em: http://www.planalto.gov. br/ccivil_03/constituicao/constituicao.htm. Acesso em 2 jul.2019.

BRASIL. Código Penal (1940). Código Penal Brasileiro. Disponível em: http://www.planalto.gov.br/ccivil_03/decreto-lei/ del2848compilado.htm. Acesso em 10 ago.2019.

CORAGGIO, J. Luis. Propostas do Banco Mundial para a educação: sentido oculto ou problemas de concepção? In.__TOMMASI, L. de.; WARDE, M. JORGE.; HADDAD, S. (organizadores). 0 banco Mundial e as políticas educacionais. 6 ed. São Paulo: Cortez, 2009

DOURADO, L. F.; CATANI, A. M.; OLIVEIRA, J. F. de. Transformações recentes e debates atuais no campo da educação superior no Brasil. In: (org.) Política e gestão da educação superior: transformações recentes e debates atuais. São Paulo: Xamã. 2003.

FERNANDES NETO, E. O fracasso dos planos neoliberais na educação brasileira.In: COSTA, A.; FERNANDES NETO.; SOUZA G. A proletarização do professor: neoliberalismo na educação. Editora Instituto José Luís e Rosa Sundermann. São Paulo, 2009.

FRIGOTTO, G. Educação e a Crise do Capitalismo Real. São Paulo: Cortez Editora, 1996.

GENTILLI, Pablo. A falsificação do consenso: simulacro e imposição na reforma educacional do neoliberalismo. Petrópolis, RJ: Vozes, 1998.

Illich, I. Sociedade sem escolas. Petrópolis: Vozes, 1976.

LEHER, R. Da Ideologia do Desenvolvimento à Ideologia da Globalização: A Educação como estratégia do Banco Mundial para o "Alívio" da Pobreza.Tese de Doutorado. USP. São Paulo, 1998

Um Novo Senhor da Educação? A política Educacional do Banco Mundial para a periferia do capitalismo. Revista Outubro. São Paulo, 2001.

LIBÂNEO, J. Carlos. Escola pública brasileira, um sonho frustrado: falharam as escolas ou as políticas educacionais?In: LIBÂNEO, J. CARLOS; SUANNO, M. V. ROSA. (Orgs.) Didática e escola em uma sociedade complexa. CEPED. Goiânia, 2011.

LUKÁCS, G. Para uma ontologia do ser social I. São Paulo: Boitempo Editorial, 2012
Para uma ontologia do ser social II. São Paulo: Boitempo Editorial, 2013.

MASCARO, Leandro Alysson. Estado e forma política. São Paulo: boitempo, 2013

MAZZUCCHELLI, F. A contradição em processo: o capitalismo e suas crises. São Paulo : Brasiliense, 1985.

MÉSZÁROS, I. A crise estrutural do capital. Revista Outubro. № 04. São Paulo, 2000.

O século XXI, socialismo ou barbárie? São Paulo: Boitempo, 2003.

OLIVEIRA, Romualdo; ADRIÃO, Theresa (Orgs.). Gestão, Financiamento e direito à educação: análise da Constituição Federal e da LDB. 3 ed. São Paulo. Xamã, p.13, 2007.

OLIVEIRA, Dalila A. Política educacional nos anos 1990: educação básica e empregabilidade. In: DOURADO, Luiz F. ; PARO, Vitor H. (org). Políticas públicas \& educação básica. São Paulo: Xamã, 2001.

PACHUKANIS, E. B. A teoria geral do direito e o marxismo. São Paulo: Renovar, 1989.

PADILHA, Rodrigo. Direito Constitucional. $4^{\mathrm{a}}$ ed. rev. e atual. ampl. São Paulo: Método, 2014

RANIERI, N. B. S. Teoria do Estado: do Estado de Direito ao Estado Democrático de Direito. São Paulo. Manole, 2013.

RICCITELLI, Antonio. Direito Constitucional: teoria do Estado e da Constituição. São Paulo: Manole. 2007.

SAMPAIO, José Adércio Leite. Direitos fundamentais: retórica e historicidade. Belo Horizonte. DelRey, 2004

SANTOMÉ, J. Torres, PARASKEVA, J. M., \& APPLE, M. W. (Orgs.). Ventos de desescolarização:a nova ameaça à escolarização pública. Lisboa: Plátano, 2003.

SOARES, M. C. Couto. Banco Mundial: políticas e reformas. In._. TOMMASI, L. de.; WARDE, M. JORGE.; HADDAD, S. (organizadores). 0 banco Mundial e as políticas educacionais. 6 ed. São Paulo: Cortez. 2009.

VASCONCELOS, Maria.Educação na casa: perspectivas de desescolarização ou liberdade de escolha? Pro-Posições (Unicamp), v. 28, p. 122-140, 2017.

VIEIRA, S. Lerche. Educação Básica: política e gestão da escola. Coleção formar. Fortaleza: Liber Livro. 2008.

. A Educação nas Constituições Brasileiras: texto e contexto. Revista Brasileira de Estudos Pedagógicos, Brasília, v. 88, n. 219, p. 291-309, maio/ago. 2007. Disponível em: http:// emaberto.inep.gov.br/index.php/rbep/article/view/749. Acesso em 15 ago. 2019. 